\title{
Retail Exposures Credit Scoring Models for Chinese Commercial Banks
}

\author{
Yihan Yang ${ }^{1}$, Guangli Nie ${ }^{2}$, and Lingling Zhang ${ }^{1,2, *}$ \\ ${ }^{1}$ School of Management, Graduate University of Chinese Academy of Sciences, \\ Beijing 100190, China \\ ${ }^{2}$ Chinese Academy of Sciences Research Center on Fictitious Economy and Data Science, \\ Beijing 100190, China \\ nkyangyihan@yahoo.com.cn, sdungl@163.com, zhangll@gucas.ac.cn
}

\begin{abstract}
This paper firstly discussed several credit scoring models and their development history, then designed the target system of individual credit scoring with individual housing loans data of a stated-owned commercial bank and logistic method, and established an individual credit scoring model including testing. Finally, the paper discussed the application of the individual credit scoring model in consumer credit domain, and brought forward corresponding conclusions and policies.
\end{abstract}

Keywords: Credit Scoring; Consumer Credit; Logistic Regression.

\section{Introduction}

With the rapid advancement of our society in recent years, people's consumption and investment concept has changed greatly. The individual consumption loan has become an important financing channel for personal consumption. Individual consumption credit business, such as housing credit, automobile credit has greatly developed. However, with the rapid development of individual consumption credit in Chinese commercial banks, default events of individual consumption credit business happened a lot, and the level of consumption credit risk assessment needs to be improved immediately. Therefore, study on the individual consumption credit risk has important theoretical value and practical significance.

The New Basel Capital Accord not only built the minimum capital adequacy ratio which covers the sources of credit risk, market risk, and operational risk, supervision and inspection, and market constraints, but also put forward Standard Approaches and IRB (Internal Rating-Based Approaches) to measure credit risk. It pointed out that banks with full conditions should implement IRB and estimated customers' PD (Probability of Default) by building models with historical data [5]. Compared with the old Capital Accord of 1998, the New Capital Accord took the estimated value of commercial banks' internal rating system as input parameters for the capital calculation, which was a major innovation. These formulas are based on modern risk management technology, involving a large number of mathematical statistics, as well as quantitative risk analysis, which is of great help to strengthen the internal risk management.

\footnotetext{
${ }^{*}$ Corresponding author.
} 


\section{Customer Credit Rating and Its Development}

From the development history of international commercial banking, we could see that the customer credit rating of commercial banks has evolved from Expert System, Credit Scoring, to the Probability of Default Model. Due to the relatively short operating history of China's commercial banks and their lack of experience in data analysis, most commercial banks still widely use the more traditional Credit Scoring method.

\subsection{Expert System}

Expert System is a traditional method of credit analysis which relies on credit experts' professional knowledge, skills and experience, uses a variety of specialized analysis tools, analyzes key elements and then makes a comprehensive assessment of credit risk based on subjective judgments. Table 1 summarizes some influential indicators

Table 1. Main Qualitative Indicators

\begin{tabular}{|c|c|}
\hline \multirow[t]{5}{*}{ CAMEL } & Capital Adequacy \\
\hline & Asset Quality \\
\hline & Management \\
\hline & Earnings \\
\hline & Liquidity \\
\hline \multirow[t]{5}{*}{$5 \mathrm{C}$} & Character \\
\hline & Capacity \\
\hline & Capital \\
\hline & Collateral \\
\hline & Condition \\
\hline \multirow[t]{5}{*}{$5 \mathrm{P}$} & Personal \\
\hline & Purpose \\
\hline & Payment \\
\hline & Protection \\
\hline & Perspective \\
\hline \multirow[t]{3}{*}{$3 \mathrm{~F}$} & Management Factor \\
\hline & Financial Factor \\
\hline & Economic Factor \\
\hline \multirow[t]{7}{*}{ CAMPARI } & Character \\
\hline & Ability \\
\hline & Margin \\
\hline & Purpose \\
\hline & Amount \\
\hline & Repayment \\
\hline & Insurance \\
\hline \multirow[t]{6}{*}{$6 \mathrm{~A}$} & Economic Aspects \\
\hline & Technical Aspects \\
\hline & Managerial Aspects \\
\hline & Organizational Aspects \\
\hline & Commercial Aspects \\
\hline & Financial Aspects \\
\hline
\end{tabular}


both at home and abroad, mainly CAMEL system, 5C elements, CAMPARI elements, $5 \mathrm{P}$ elements, $3 \mathrm{~F}$ elements, $6 \mathrm{~A}$ elements, and so on.

\subsection{Credit Scoring}

Credit scoring model uses observable characteristic variables of the borrower, and calculates a numerical value (score) to represent the debtor's credit risk and classify borrowers into different risk levels. For individual customers, observable characteristic variables include income, assets, age, occupation, as well as place of residence, and so on. The key of credit scoring model is to choose characteristic variables and determine their respective weight. At present, the most widely used score models include Linear Probability Model, Logit Model, Probit Model, Decision Tree Method, ANN(Artificial Neural Networks), as well as SVM(Support Vector Machine).

Credit scoring began with Beaver's single-variable analysis of 79 bankrupt companies [1]; Altman put forward the Z score model and ZETA score model based on multivariate statistics [3]; Matin, Ohlson and Wigintonfor for the first time used Logit model to analyze the enterprise bankruptcy [6]; Katz et al. used discriminant analysis in credit scoring study; $\mathrm{Ou}$ and Penman adopted Probit model to predict corporate bankruptcy. In the application of artificial intelligence, Lee et al. made empirical analysis on credit scoring samples with two decision tree methods as CART and MARS [9]; Gestel et al., Min \& Lee, Liu Min, Lin Chengde adopted support vector machine method in bankruptcy prediction and credit assessment, proving that the machine learning performance was superior to the traditional method [14].

This article focused on the application of Logit model,. Westgaard \& Wijst used the enterprise's micro-economic information, integrated the financial indicators, and estimated the default probability of the portfolio in retail banking with Logit model. The method was used in the credit risk management of Norwegian business sector, achieving very good results [4]. Lanine and Vennet analyzed characteristics of banks inclining to bankruptcy with Logit model and trait recognition method, targeted at the confusion and crisis of Russian banks in the 1990s [10].

\subsection{Probability of Default Model}

Since the 1990s, a number of models that could directly calculate the default probability emerged, including Moody's RiskCalc model and Credit Monitor, KPMG's Riskneutral Pricing Model and the Mortality Model.

Compared with the traditional Expert System and Credit Scoring method, the Probability of Default Model could directly estimate the customer's probability of default, and therefore had a high requirement for historical data, requiring commercial banks to establish a consistent and clear-cut definition of default, and to accumulate historical data of at least five years. According to the status quo of China's banking industry, commercial banks should combine default probability model with the traditional credit scoring, expert system, which could help raise the level of credit risk assessment. 


\section{The Process of Modeling}

This paper designed the target system of individual credit scoring with individual housing loans data of a stated-owned commercial bank for credit scoring model verification. If we apply the framework to other credit products, such as car loans, personal consumption loans, and so on, we just need change the relative elements and maintain the overall framework. Flow chart of the model is shown in Fig. 1 below:

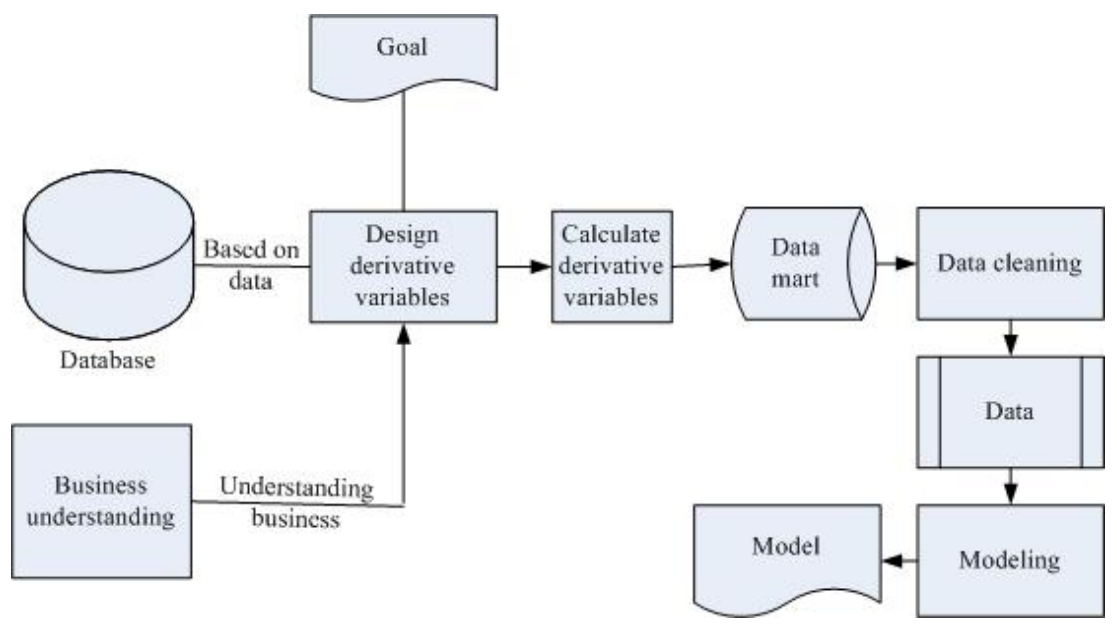

Fig. 1. Flow Chart of the Model

\subsection{Establishing the Indicator System}

The dependent variable for Logistic regression is discrete, and the predicted value of the model is output in form of probability [15]. Similar to the discriminant analysis, Logistic regression can deal with the issue of classification, while the difference is that Logistic regression requires neither normal distribution nor the equal variance assumption [9]. Personal credit data rarely meet with these two assumptions, so Logistic regression is more suitable for credit scoring models. The regression model built with Logistic distribution curve is also known as Logit model. The equation for logic model is as follows:

$$
\operatorname{Ln}\left(\frac{P}{1-P}\right)=\beta_{0}+\beta_{1} X_{1}+\cdots \cdots+\beta_{n} X_{n}
$$

We established the indicator system and listed quantitative indicators of the individual housing loan credit scoring model as Table 2 shows.

\subsection{Data Collection}

According to the definition of "normal loan" and "non-performing loan", we collect all individual housing loan samples covering all the indicators. Data in observation 
period generate variable $\mathrm{X}$; performance period comes after the observation period; we watch the performance of samples in this period, and generate variable $\mathrm{Y}$.

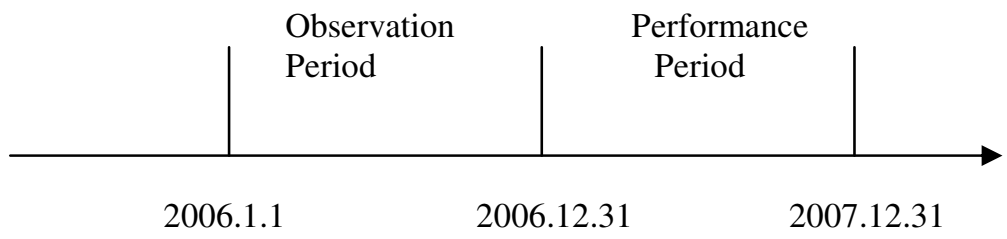

Fig. 2. Observation period \& performance period

Data processing in observation period: According to the data available, we choose the observation period from 2006.1.1 to 2006.12.31, which is a whole year, preventing some holidays from impacting the model, and $X_{i}$ is from data in this period.

We choose the performance period from 2007.1.1 to 2007.12.31, and determine the customer credit according to the customer's performance in this period.

\subsection{Data Cleaning}

According to the data available and China's actual situation, we identify the model's main factors $X_{i}$ and the dependent variable Y (i $=12 \ldots \ldots$. 2 ). Main factors and data cleaning methods are shown in table 2 .

Table 2. Main factors data cleaning

Explanatory Variables $X_{\mathrm{i}} \quad$ Cleaning Methods

Repayment Ratio (the amount

of repayment / loans) $X_{1}$

Down payment ratio (the amount of down payment /loans) $X_{2}$

Loan percentage $X_{3}$
We clean out those customers whose accounts were settled before 2006

If a customer has over one record, we choose the last record.

Loan period $X_{4}$ 
Table 2. (Continued)

\section{Non-repayment period ratio(non-repayment \\ periods/total periods) $X_{5}$}

For a record who has over one due bill, we choose the sum; for a record whose number of nor-repayment periods is 0 , we clean it out.

Asset $X_{6}$

Gender $X_{7}$

This indicator is generated in SAS system according to customers' ID number

Age $X_{8}$

Ibid

The number of cumulative overdue times accumulated in SAS system is shown in Fig. 3 below:

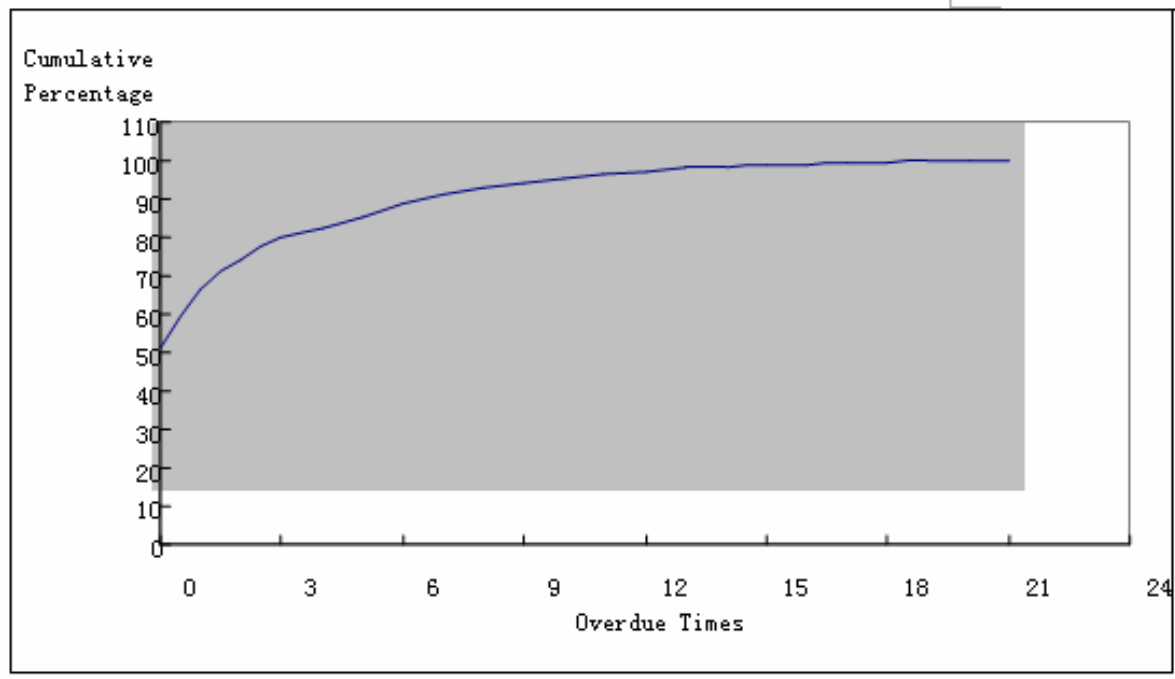

Fig. 3. Chart of cumulative times

As can be seen from the chart, when the cumulative overdue times are over 7 , the overdue frequency changes very little, that's to say, the possibility for those customers to change into "good guys" is very small, so we take those whose cumulative overdue frequence is $\geq 7$ as bad customers.

$Y=1$ if bad customers(cumulative overdue frequence $\geq 7$ in 2007)

$\mathrm{Y}=0$ if good customers (cumulative overdue frequence $<7$ in 2007)

From the chart, we could see that 


$$
\text { Credit Score }=1-\frac{1}{1+\exp \left(\sum_{i=1}^{N}-\beta_{i} X_{i}\right)}
$$

$X_{\mathrm{i}}$ is the value of the explanatory variable $\mathrm{I} ; \beta_{i}$ is the corresponding weight; $\mathrm{N}$ is the number of explanatory variables. The Score here is the ultimate value and the probability of being a good customer in this model. Therefore, the higher the value, the better the result is.

\subsection{Logit Regression}

We receive a total of 1317 records after data cleaning, and then we build a model with these 1317 customers and make corresponding parameter test.

Table 3. Result of logit regression

\begin{tabular}{|c|c|c|c|}
\hline Independent Variable & $\begin{array}{l}\text { Coefficient } \\
\text { Estimation }\end{array}$ & $\begin{array}{l}\text { Significance } \\
\text { Test } \\
\text { (Wald Test) }\end{array}$ & $\begin{array}{l}\text { Goodness of } \\
\text { Fit Test }\end{array}$ \\
\hline Age & 0.0759 & 0.0004 & \\
\hline Total Assets(RMB) & $-9.38 \mathrm{E}-07$ & 0.0326 & $\begin{array}{l}\text { HL test is } \\
\text { not }\end{array}$ \\
\hline Repayment Ratio & -0.9711 & 0.0075 & significant \\
\hline Down payment ratio & -426.7 & 0.0024 & $\begin{array}{l}(0.8425) \text {. } \\
\text { The fit data }\end{array}$ \\
\hline Loan period & -0.0168 & 0.0002 & $R^{2}$ \\
\hline $\begin{array}{l}\text { Non-repayment period } \\
\text { ratio }\end{array}$ & -2.4466 & 0.0022 & $\begin{array}{l}\text { is } 0.9175 \text {, } \\
\text { which } \\
\text { means the } \\
\text { fitness is } \\
\text { good. }\end{array}$ \\
\hline
\end{tabular}

The relevant information of Logistic regression shows that the fitness is good. Hosmer-Lemeshow test (HL test) is not significant, $R^{2}=0.9175$ shows that the accuracy of the model is higher. Gender statistics are not significant and doesn't enter the model. The results of "Association of Predicted Probabilities and Observed Responses" show the correlation between probability forecasting and observed dependent variables. The Percent Concordant is 94.7\%, and the Percent Discordant is 3.8\%, which shows that there is a strong correlation between the predicted and observed values at the current level, and the regression model has a strong predicting ability. 


\subsection{Model Diagnosis}

We operate a linear diagnosis on the model, and the result is shown in Table 4 below.

Table 4. Linear diagnosis

\begin{tabular}{llll}
\hline Independent Variable & Freedom & Tolerance & VIF \\
\hline Age & 1 & 0.9808 & 1.01957 \\
Total Assets(RMB) & 1 & 0.93513 & 1.06937 \\
Repayment Ratio & 1 & 0.98616 & 1.01403 \\
Down payment ratio & 1 & 0.70581 & 1.41682 \\
Loan period & 1 & 0.57696 & 1.73322 \\
Loan quota & 1 & 0.66951 & 1.49362 \\
Non-repayment period ratio & 1 & 0.56939 & 1.75627 \\
Age & 1 & 0.55633 & 1.7975 \\
\hline
\end{tabular}

Usually we set $\mathrm{VIF}=10$ or Tolerance $=0.1$ as threshold value. When $\mathrm{VIF}<10$, or Tolerance $>0.1$, we think the variables selected have no obvious collinearity. The VIF of variable selected in this model is less than 5, so the model has no collinearity problem.

\subsection{Model Explanation}

(1)The estimated coefficient of the age factor is positive, having a negative correlation with the final score value. This is because customers in the database are aged 21-58. Customers with lower ages (generally 25-40 years old) are the main force in society, whose bright future and better income guarantee a lower loan default rate. Customers aged 45-58 are close to retirement, so the default rate is relatively higher. The result here happens to coincide with the personal credit score standard of China Construction Bank. The bank gives customers aged of 36-50 a credit score of 6 , while those aged 50 and above a credit score of 4 (China Construction Bank Web site). This shows that above a certain limit of age, the older the customer, the higher the default rate.

(2)The estimated coefficient of the age factor is negative, having a positive correlation with the final score value. The more the assets are, the lower the default rate is. It is worth noting that the estimated coefficient of this indicator is relatively small in this model, and the weight appears to be low. Considering the reality that China's personal property declaration system is not perfect, and there is a certain degree of hidden income, we argue that the actual "monthly income" indicator would be of greater importance to personal credit than that in this paper.

(3) The estimated coefficients of Repayment Ratio, Down payment ratio, and Nonrepayment period ratio are negative, having a positive correlation with the final score value. The estimated coefficient of the loan quota factor is positive, having a negative 
correlation with the final score value, which shows that the higher the loan quota is, the larger the loan amount, and thus the bigger the probability of default; this is in line with the real business. It is worth noting that the estimated coefficient of the loan period factor is negative. According to general analysis of business, loans with longer duration will have more uncertainty, leading to greater likelihood of default, that is, the loan period should have had a positive correlation with the default rate. But the model here gives a negative coefficient. One explanation could be that the length of the loan agreement is influenced by the owner's risk attitude. Cautious customers are inclined to have loans with longer periods. Most Chinese customers of housing loans are risk avoiding, and their default probability is relatively low, so the loan period has a negative correlation with the default probability. This result shows that in China's current data accumulation, because of all the banks' scrutiny, customers who can get loans of longer periods generally have good credit.

\section{Conclusions}

Credit risk is the most dangerous one in financial industry. The construction of evaluation model of individual credit is urgently needed. Based on this, this article discussed the method of evaluating customer credit. In combination with the theory of personal credit risk, we choose Logistic regression with data of individual housing loan from some Chinese Commercial Bank, and make theoretical research and empirical analysis on the evaluation of individual credit risk management in Chinese Commercial Banks. The model based on Logistic regression shows that there are six indicators that greatly affect individual credit evaluation as follows: age, assets, loan quota, Repayment Ratio, Down payment ratio, and Non-repayment period ratio.

Through comparison between conclusions at home and abroad, it could be concluded that the model is right and effective, and the empirical result is consistent with the real experience. However, in the process of constructing the model, some basic information of customers which is very important to the construction of the model, such as education background, professions, marriage status, etc. is not taken into consideration due to bad quality of data in commercial bank. Therefore, we strongly suggest that China should establish a united basic database of individual credit information to obtain comprehensive data and mark the client credit more accurately. Because the samples in this article are consumption credit data taken from a typical Chinese commercial bank, the finally constructed individual credit scoring model can be a good reference for other commercial banks to evaluate individual consumption credit.

\section{Acknowledgements}

This research has been partially supported by a grant from National Natural Science Foundation of China (\#70621001, \#70531040, \#70501030, \#70472074), Beijing Natural Science Foundation (\#9073020). 


\section{References}

1. Beaver, W.: Financial rations are predictors of failure. Journal of Accounting Research (4), Suppl. 71-111 (1966)

2. Altman, E., Haldeman, N.P.: ZETA analysis: A new model to identify bankruptcy risk of corporations. Journal of Banking and Finance (1), 29-54 (1977)

3. Altman, E., Narayanan, P.: An International Survey of Business Failure Classification Models. Financial Markets, Institutions and Instruments 6(2) (1997)

4. Westgaard, S., Wijst, N.: Default probabilities in a corporate bank portfolio: A logistic model approach. European Journal of Operational Research (135), 338-349 (2001)

5. Basle Committee. Basle Committee on Banking Supervision. The New Basel Capital Accord. Bank for International Settlements, Basle (April 2003)

6. Wiginton, J.C.: A note on the comparison of logit and discriminant models of consumer credit behavior. Financial Quant. Anal. (15), 757-770 (1980)

7. Press, J., Wilson, S.: Choosing between Logistic regression and discriminant analysis. Journal of American Statistical Association 73(7), 699-705 (1978)

8. Scott, D.F., Martin, J.D.: Industry Influence on Financial Structure. Financial Management, 67-73 (Spring 1975)

9. Shin, K.S., Lee, T.S., Kim, H.J.: An application of support vector machines in bankruptcy prediction model. Expert Systems with Applications (28), 127-135 (2005)

10. Lanine, G., Vennet, R.V.: Failure prediction in the Russian bank sector with logit and trait recognition models. Expert Systems with Applications (30), 463-478 (2006)

11. Laitinen, E.K., Laitinen, T.: Bankruptcy prediction: application of the Taylor's expansion in logistic regression. Int. Rev. Financial Anal. 9(4), 327-349 (2000)

12. Flagg, J.C., Giroux, G.A., Wiggins, C.E.: Predicting corporate bankruptcy using failing firms. Rev. Financial Econ. (1), 67-78 (1991)

13. Kay, O.W., Warde, A., Martens, L.: Social differentiation and the market for eating out in the UK. Int. J. Hosp. Manage. 19(2), 173-190 (2000)

14. Gestel, T.V., Baesens, B., Suykens, J.A.K., Poel, D.V., Baestaens, D.E., Willekens, M.: Bayesian kernel based classification for financial distress detection. European Journal of Operational Research (2005)

15. Cox, D.R., Snell, E.J.: Analysis of Binary Data. Chapman \& Hall, London (1989) 